\title{
O ENSINO DE INGLÊS EM UMA CIDADE DO INTERIOR DA BAHIA: UM BREVE RECORTE
}

\section{THE TEACHING OF ENGLISH IN A CITY FROM DE INTERIOR OF BAHIA: A SMALL SAMPLE}

\author{
Domingos Sávio Pimentel Siqueira ${ }^{1}$, Sigrid Rochele Gusmão Paranhos Magalhães ${ }^{2}$
}

\begin{abstract}
RESUMO: O ensino da língua inglesa, hoje vista como uma língua franca global, deve contribuir para que o aluno seja um cidadão mais crítico, livre de preconceitos, pronto para aceitar as diferenças e a pluralidade cultural. Desta forma, pode-se postular que o verdadeiro propósito em ensinar línguas estrangeiras no contexto contemporâneo é aquele de formar indivíduos capazes de interagir com pessoas de variadas culturas. Tomando como base uma pesquisa sobre o ensino de Inglês como Língua Estrangeira em escolas da cidade de Caetité/Bahia, este artigo objetiva discutir como ocorre esse processo de ensinoaprendizagem no contexto de globalização e busca apontar caminhos para um ensino mais significativo e crítico no lócus específico.
\end{abstract}

PALAVRAS-CHAVE: Ensino da Língua Inglesa; Globalização; Inglês como Língua Franca; Brasil.

ABSTRACT: The teaching of English, seen today as a global lingua franca, is supposed to contribute for the learner to become a more critical citizen, free of prejudices, ready to accept differences and cultural plurality. Therefore, it can be argued that the real purpose of teaching foreign languages in the contemporary context is to form individuals able to interact with people from different cultural backgrounds. Based on a research study about the teaching of English as a foreign language in regular schools in the city of Caetité/Bahia, this article aims to discuss how the teaching-learning process occurs in the context of globalization, while seeking to suggest alternatives for a more meaningful and critical teaching in that specific reality.

KEYWORDS: English language; Globalization; English as a lingua franca; Brazil.

\section{Introdução}

Parece tratar-se de uma grande obviedade, mas é sempre importante destacar que nenhuma língua é (foi ou será) una e homogênea. Com o inglês, hoje o idioma de maior

\footnotetext{
${ }^{1}$ Doutor em Letras e Linguística pela UFBA. Professor Associado do Departamento de Letras Germânicas do Instituto de Letras da UFBA

${ }^{2}$ Mestra em Língua e Cultura pela Universidade Federal da Bahia (UFBA). Professora Auxiliar do Departamento de Ciências Humanas - Campus VI/Caetité, da Universidade do Estado da Bahia (UNEB).
} 
expansão e penetração mundial, indiscutivelmente, não seria diferente, pois dentre algumas de suas características mais marcantes no desenrolar dos tempos atuais, chama a atenção o fato de ser essa língua falada por uma quantidade bem maior de não-nativos do que de nativos. Nessas circunstâncias, é fácil deduzir que a língua inglesa agrega, na sua viagem pelo planeta, marcas e facetas próprias de cada lugar, tornando-se, assim, porta-voz de uma imensa variabilidade cultural e ideológica. Diante de tal panorama, segundo Rajagopalan (2005, p. 150-151), “[a] língua inglesa que circula no mundo, que serve como meio de comunicação entre os diferentes povos do mundo de hoje, não pode ser confundida com a língua que se fala nos Estados Unidos, no Reino Unido, na Austrália ou onde quer que seja”.

Logo, ao ensinar uma língua estrangeira (doravante LE) como o inglês, deve-se ter o cuidado de não impor aos educandos acepções e valores das chamadas culturas hegemônicas desse idioma, como é de costume em muitos contextos, posto que essa língua é hoje concebida como uma língua internacional ou língua franca global e, portanto, nas interações cada vez mais comuns entre não-nativos, coloca em contato muitas 'linguaculturas ${ }^{3}$, ou como aponta Mendes (2012), "muitos mundos culturais". Por essa razão, não cabe mais aos professores de inglês adotar, ainda que de forma inconsciente, uma "atitude colonizada", levando a cabo práticas pedagógicas hoje consideradas anacrônicas, pelo menos do ponto de vista ideológico (MOITA LOPES, 1996). Ou seja, deve-se evitar, sobretudo, uma subjugação cultural e linguística que, normalmente, se dá através da desvalorização da língua e cultura maternas do aluno. Por isso, faz-se necessário repensar a prática docente que, muitas vezes, assume uma "atitude exageradamente positiva de quase adoração pela cultura [da língua alvo]" (MOITA LOPES, 1996), e se desenvolve de maneira que "tem mais a ver com acomodação de que com acesso ao poder" (PENNYCOOK, 2007, p. 28).

Isto posto, torna-se urgente e desafiador refletir sobre o ensino de inglês no Brasil, porque as desigualdades sociais são gritantes, a educação quase sempre beira o sofrível e uma maioria já bastante conhecida não tem acesso a um ensino de LE de qualidade. Nesse sentido, Moita Lopes (2008) reforça que deve haver uma preocupação constante em se pensar em ensinar inglês como LE em termos da realidade local, já que sempre existirá a necessidade de estudos mais amplos sobre como se processa o ensino e a aprendizagem dessa língua nos espaços espalhados pelo mundo que, como se sabe, por menores e mais remotos que sejam, têm se tornado cada vez mais complexos.

\footnotetext{
${ }^{3}$ Termo cunhado por Agar (1994). No original, languaculture. O autor busca sintetizar 'língua' e 'cultura' em uma só palavra. Assim, 'linguacultura', para ele, refere-se à necessária conexão entre esses dois elementos.
} 
O ensino de inglês neste cenário de complexidades, portanto, traz muitos desafios para os docentes, visto que o domínio da língua inglesa pode abrir diversas portas para mundos e culturas cada vez mais interessantes e outrora muito distantes. Mas também pode se tornar para aqueles à margem do atual processo de globalização um forte instrumento de exclusão e de opressão, caso esteja disponível apenas para alguns privilegiados que o adquirem a peso de ouro.

Com base nisso, o objetivo deste artigo, fruto de reflexões de uma pesquisa acadêmica, é discutir o ensino de inglês em três escolas do Ensino Fundamental II ( $6^{\circ}$ ao $9^{\circ}$ ano) da cidade de Caetité/Bahia, tendo como ponto de investigação as concepções que os professores têm da língua alvo no contexto de globalização. Para tanto, o trabalho foi desenvolvido dentro de uma abordagem qualitativa, seguindo os princípios da pesquisa etnográfica de base interpretativista e à luz dos estudos teóricos da Linguística Aplicada.

\section{O inglês como língua global e suas diversas implicações}

A expansão mundial do inglês, segundo Pennycook (1995), não é apenas a expansão da língua, mas, acima de tudo, a expansão de muitos ideais do mundo ocidental e características da chamada modernidade, tais como progresso, liberalismo, capitalismo, democracia, entre outros. Frente a tal panorama, de natureza cada vez mais desafiadora, esse mesmo autor aposta numa Linguística Aplicada que leve aprendizes a se apropriarem da língua alvo para "formular contra-discursos aos discursos e práticas que promovam a desigualdade e dependência" (PENNYCOOK, 1995, p. 52).

Como se sabe, a aprendizagem de uma nova língua envolve os mais diversos aspectos, que vão desde o linguístico ao cultural, ao político, ao ideológico, etc. Em outras palavras, a sala de aula de línguas, além de ser um espaço de aquisição de um outro sistema linguístico, deve ser, acima de tudo, um ambiente propício para se fomentar a discussão de questões ideológicas que tratam do cotidiano do educando, dos diversos tipos de preconceitos existentes em nossa sociedade, das relações entre etnias, da vida dos silenciados, dos mundos que habitam as periferias, do eu, do outro, etc. Apesar de muitos professores não encararem sua prática sob tal perspectiva, deve-se levar em consideração que o espaço escolar é a própria representação do mundo e não um mundo à parte. Ou seja, quando se concebe língua como prática social, todos os aspectos da vida em sociedade devem se fazer presentes na sala de aula, levando os alunos, portanto, a entenderem que a aprendizagem de uma língua como o inglês, por exemplo, potencializa a sua participação no espaço global de maneira igualitária. 
Sob essa ótica, é possível afirmar que uma nova língua deve ser ensinada de maneira que o aluno possa compreender o outro, o diferente, o estrangeiro, sem perder de vista as marcas de sua língua primeira, sua identidade, sua(s) cultura(s). O acesso a uma nova 'línguacultura' deve possibilitar a formação de diversos 'entrelugares' (BHABHA, 1998), ou zonas de contato, e proporcionar ao aprendiz a oportunidade de se aventurar por essas esferas de forma segura e prazerosa, pois o inglês, na sua condição de língua global, carrega em seu bojo traços de diferentes ingleses que aproximam mundos culturais distintos de maneira jamais vista.

A aprendizagem de uma língua falada em nível mundial como o inglês, inegavelmente, poderá inserir o aprendiz nessa rede global de aldeias (BLOMMAERT, 2010), de forma mais plural, fazendo com que as sociedades se façam cada vez menos excludentes. Essa língua deverá, afinal, contribuir para que o futuro usuário aumente seu repertório linguístico-cultural, tornando-se um cidadão mais politizado, livre de certos preconceitos, pronto para aceitar as diferenças intrínsecas à humanidade, à pluralidade cultural, sem deixar de ser ele mesmo. Sob esse prisma, cabe ao professor adotar uma firme postura crítica e reflexiva, pois como assinala Giroux (1996, p. 570), aludindo ao trabalho pioneiro de Paulo Freire, “ensinar não é simplesmente estar na sala de aula, mas estar na história, na esfera mais ampla de um imaginário político [em busca de] mudanças significativas na minimalização do grau de opressão na vida das pessoas”.

Em tal cenário, a escola, como um espaço democrático por natureza, necessitará, de fato, levar em conta toda a diversidade mundial de forma consciente e responsável, através de um ensino que possa, entre tantas outras coisas, promover nos educandos o desenvolvimento de uma cidadania global, considerando a pluriculturalidade cada vez mais intensa dessa sociedade interligada e em constante interação.

Ademais, como aponta Pennycook (2001, p. 78), com ou sem resistência, "o inglês está no mundo e o mundo está em inglês”. Entretanto, com a expansão da língua mundo afora, muitos aspectos a ela relacionadas começam a ser postos em cheque, como a sua posse por um determinado povo ou nação. Crystal (2003), só para ilustrar tal debate, argumenta que nenhuma nação pode requerer a custódia da língua inglesa, visto que, na sua viagem por todos os cantos do planeta, ela se tornou uma língua internacional. Portanto, "ninguém mais a tem, aliás, todos aqueles que a aprenderam a possuem - e podem compartilhar dela, o que seria mais correto afirmar - e, além disso, possuem o direito de utilizá-la da maneira como quiserem" (CRYSTAL 2003, p. 3), uma vez que apropriar-se de uma língua é torná-la 
instrumento da mente, compreendendo que "a verdadeira proficiência se dá ao se tirar vantagens sobre ela, fazendo com que ela seja de fato real" (WIDDOWSON, 1994, p. 384).

\section{A ideia de uma língua franca mundial}

O inglês se expandiu pelo planeta afora cavalgando em movimentos de poder, seja político, tecnológico, econômico ou militar. Entretanto, em termos de difusão, se olharmos para trás e associarmos a semelhança que ocorreu com o latim, o qual se fragmentou em muitos dialetos, se desmembrando, consequentemente, em diversas outras línguas, é incerto assegurar que o inglês continuará predominando em escala mundial como língua global de base semelhante, embora essa língua possa contar com a emergência cada vez mais frequente de inúmeros outros 'ingleses'.

São trajetórias e realidade diferentes, é bem verdade. A favor do inglês em manter sua base está o processo atual de globalização que, de alguma forma, a partir da expansão brutal das chamadas novas tecnologias da informação e comunicação, contribui decisivamente para a difusão desse idioma por entre comunidades de fala de todos os cantos do mundo. Em escala planetária, a língua se impõe como uma realidade irreversível e as muitas controvérsias sobre o seu estatuto e sua influência sobre realidades locais se acentuam mediante tamanha proporção de interferência. Como resultado, para investigar e compreender esse fenômeno sui generis, pesquisadores de várias áreas da linguagem o enxergam a partir de diferentes perspectivas, deixando emergir uma profusão de termos e concepções como Word Englishes, World English, Inglês como língua internacional, Inglês global, inglês como língua franca, Globish, etc.

Cada uma dessas terminologias traz as suas ideologias, suas premissas e implicações, ainda que se assemelhem em vários aspectos ou se distanciem a partir de determinadas características e orientações, como acontece, a título de ilustração, com o conceito de World Englishes (WE), que trata cada inglês como uma variedade e, por outro lado, o Inglês como Língua Franca (ILF), que centra seu interesse não em variantes, mas nas interações travadas entre falantes de diferentes línguas maternas e backgrounds culturais dos mais variados.

No bojo dessa discussão, é possível identificar o trabalho de muitos estudiosos, tais como Jenkins (2006), Cogo (2010), Cogo e Dewey (2012), Siqueira e Barros (2012), Sifakis (2014), entre outros, filiados ao paradigma de ILF, uma vez que esse conceito busca descentralizar o inglês dos chamados países hegemônicos. Como se sabe, são essas nações que ainda ditam normas e padrões de um grupo de falantes nativos e que são tomados como 
base para o ensino de língua inglesa por todo o planeta, não raramente, ignorando as implicações políticas e ideológicas da própria condição do inglês como língua franca mundial.

Como bem lembra Ortiz (2006, p. 33), “nenhuma língua é franca, ela apenas desempenha, em determinados domínios, a função de ser franca". Assim, vale esclarecer, resumidamente, que o termo língua franca é uma expressão latina usada para designar a língua de contato ou a língua de relação entre grupos linguisticamente distintos com propósitos internacionais. Contudo, como veremos mais adiante, o conceito de língua franca tem sido revisitado e reconstruído à luz da realidade contemporânea, em especial devido ao fenômeno de expansão da língua inglesa em escala global, na qual o que importa são as estratégias usadas por falantes de diferentes backgrounds culturais para garantir a inteligibilidade entre si. Ou seja, cada vez mais, a preocupação é estudar e ensinar o inglês a partir de um paradigma que o enxergue como um recurso importante para a comunicação intercultural (COGO, 2015).

Desta forma, como acima mencionado, entre os mais diversos prismas utilizados para investigar o fenômeno, o Inglês como Língua Franca (ILF) é hoje consolidado como um paradigma de pesquisa com importantes resultados advindos de várias partes do planeta. Seidlhofer (2001, p. 146), só para exemplificar, postula que o termo língua franca é um sistema linguístico adicional que serve como meio de comunicação entre falantes de diferentes línguas maternas, ou uma língua através da qual os membros de diferentes comunidades de fala podem comunicar-se entre si, mas que não é a língua nativa de nenhum deles.

Assim, diante da configuração global atual, a definição de língua franca, ancorada no papel exercido pelo inglês na contemporaneidade, passa por uma reformulação e ampliação, sendo o ILF considerado pela própria Seidlhofer $(2011$, p. 7) como "qualquer uso do inglês entre falantes de diferentes línguas maternas, para os quais o inglês é o idioma de comunicação escolhido, e frequentemente a única opção". Por conta disso, tanto Seidlhofer (2011) quanto outros pesquisadores da área, diante de tal conceituação, acrescentam que, na conjuntura de fluxos globais atuais, as interações em ILF também consideram a presença de falantes nativos de inglês nas interlocuções com usuários não-nativos.

Em face dessa perspectiva, é nossa crença que os usuários dos países que não têm a língua inglesa como primeira ou segunda língua, não necessitam mais aprender o inglês como língua estrangeira (LE) nos moldes tradicionais, uma vez que é possível a esses futuros faltantes de inglês tornarem-se igualmente 'proprietários' dessa língua. É o que nos lembra Widdowson (1994, p. 385) de forma clara e inconteste: 
É uma situação de considerável orgulho e satisfação para falantes nativos saberem que sua língua é um meio de comunicação internacional. Mas a questão é que esta língua só é internacional a partir do momento em que deixa de ser deles. Ela não é uma possessão que possa ser emprestada a outras pessoas enquanto se mantém a sua guarda. As outras pessoas que a falam, de fato, a tomam como sua.

Ancorados nessa compreensão, vemos como necessária e urgente uma reavaliação do inglês ensinado nas escolas brasileiras, principalmente por se tratar do contexto globalizado em que vivemos, que requer mudanças de hábitos, quebra de barreiras, atenção à velocidade de informações, entre outros tantos fatores. Ou seja, falar, ler e entender o inglês como língua franca, portanto, torna-se fundamental também nesse contexto.

Feita essa breve incursão, na sequência, partiremos para uma discussão mais prática, trazendo para análise e reflexão dados levantados no cenário da sala de aula de inglês de um contexto escolar bastante familiar no nosso país, enfatizando as intricadas relações do professor com os alunos, com os conteúdos trabalhados e com o meio social.

\section{A pesquisa com professores de inglês na cidade de Caetité/Bahia ${ }^{4}$}

Esta pesquisa foi idealizada com o principal propósito de conhecer as percepções que os professores do contexto em pauta têm da língua inglesa nesse cenário contemporâneo. Em termos metodológicos, o trabalho seguiu os princípios da pesquisa etnográfica, essencialmente qualitativa e de cunho interpretativista (ANDRÉ, 1995; GIL, 2002). A coleta de dados ocorreu com três professores-informantes (P1, P2, P3) e em três unidades escolares (rede particular, rede estadual e rede municipal de ensino) da referida cidade. Foram visitadas cinco aulas em cada contexto, perfazendo, assim, um total de quinze aulas observadas. Os instrumentos de geração de dados utilizados foram (i) registros etnográficos (com gravação de áudio e notas de campo); (ii) questionário e (iii) entrevista semiestruturada.

Os registros etnográficos foram feitos tendo como parâmetro os seguintes temas: (a) ensino de inglês no contexto de globalização, (b) abordagens dos aspectos culturais em sala de aula; e (c) postura dos alunos nas aulas de inglês. Dessa maneira, buscamos verificar se a prática pedagógica de língua inglesa nesses espaços educacionais tem sido capaz de proporcionar ao educando condições para que ele se torne um cidadão ativo neste mundo de contatos interculturais cada vez mais frequentes.

\footnotetext{
${ }^{4}$ A cidade de Caetité, Bahia, situa-se a 645 quilômetros da capital, Salvador, e possui uma população em torno de 55 mil habitantes. É a terra do educador Anísio Teixeira e do cantor Waldick Soriano.
} 
Já o questionário foi composto por vinte e uma questões abertas e dividido em dois blocos de perguntas. O primeiro bloco, voltado para os dados pessoais, e o segundo bloco, enfocando temas específicos sobre o ensino da língua inglesa, englobou quatorze perguntas. $\mathrm{Na}$ entrevista semiestruturada foram discutidas perguntas antecipadamente elaboradas, no intuito de obtermos uma melhor compreensão das temáticas abordadas anteriormente e, da mesma forma, proporcionar aos entrevistados uma maior liberdade para expressar as suas opiniões.

Na sequência, serão discutidos, em linhas gerais e de forma sintética, os resultados que emergiram do trabalho investigativo em questão.

\section{Caminhos e reflexões sobre o ensino de inglês em uma cidade do interior da Bahia}

A partir do que revelaram os instrumentos, foi claramente acentuado nas falas, nas observações em sala de aula e respostas ao questionário, o fato de a língua inglesa falada principalmente nos países considerados hegemônicos, Inglaterra e Estados Unidos, ser vista pelos professores participantes como a língua de referência mundial, de supremacia, de poder, que poderá levar os aprendizes a uma condição bastante privilegiada, caso a dominem de forma competente. Porém, nos pareceu evidente que, no contexto analisado, ainda é relativamente pequeno o número de pessoas que utilizam o inglês com certa frequência e um nível razoável de proficiência, em especial, os alunos do espaço público de ensino do referido município.

Visto por este ângulo, assume-se, portanto, que um não falante de inglês nos tempos de hoje é, de certa forma, estigmatizado socialmente e, não raramente, excluído das oportunidades práticas que o domínio do idioma pode proporcionar. Não obstante, é curioso salientar que, em nenhum momento, os professores colaboradores registraram que o inglês poderia ter um caráter formador educativo e libertário para o aprendiz. Algumas das falas abaixo revelam tal quadro:

[P1] A língua inglesa é a língua dos negócios, das viagens, do computador, é a língua que falamos com o mundo todo.

[P2] A língua inglesa hoje é uma necessidade universal.

[P3] De suma importância para qualquer área profissional.

Diante de tais evidências, é possível apontarmos que, a realidade investigada, até este momento, ainda se encontra muito distante do ideal de uma língua franca, de contato. Em situação alguma, o inglês, nessa condição global, foi mencionado pelos sujeitos da pesquisa, 
nos levando a concluir que, aparentemente, eles desconhecem esse conceito. $\mathrm{O}$ que observamos é que os participantes se empenham na busca pela excelência e correção da pronúncia à luz do modelo do falante nativo, especificamente o padrão norte-americano ou britânico, concebendo-o como símbolo de status e superioridade, como revela abaixo o excerto de uma aula observada:

\begin{abstract}
Um aluno faz a seguinte leitura: What about your free time activities? How often do you hang out with friends? P3 diz então que o aluno não foi merecedor da pontuação total atribuída a essa atividade, pois não pronunciou adequadamente as palavras about e hang out, uma vez que essas palavras soaram muito pesadas. Por fim, aconselhou ao estudante: Tem que falar com mais naturalidade. Ouvir o CD mais, para ter uma pronúncia melhor, uma pronúncia forte, [...] more you listen, more you learn!
\end{abstract}

A partir desse recorte, podemos inferir que é preciso operar em várias frentes, principalmente na formação inicial e continuada dos professores, já que, em uma perspectiva mais ampla, são eles os agentes de empoderamento dos aprendizes quando se engajam em um processo de democratização de um conhecimento que pode, de fato, mudar a vida das pessoas. Sob esse prisma, Moita Lopes (1996, p. 43) advoga que "a aprendizagem de uma LE, ao contrário do que podem pensar alguns, fornece talvez o material primeiro para tal entendimento de si próprio e de sua própria cultura". Segundo esse autor, a posição que a língua inglesa assume em todos os setores da vida nacional, confirma a referida alienação do povo brasileiro em relação ao estrangeiro (MOITA LOPES, 1996). Certamente, por sermos um país ex-colonizado, “este processo de identificação com o 'outro', o colonizador, ou melhor, com a sua superioridade, vai levar o colonizado à imitação do colonizador em todos os níveis" (MOITA LOPES, 1996, p. 49).

Dessa maneira, a fim de evitar que ocorra tal reprodução de postura e comportamento, o ensino de inglês, neste cenário de globalização, precisa ser capaz de levar o aluno à reflexão crítica, ao entendimento da diversidade da língua e da multiplicidade de culturas que estão presentes em todos os lugares. Isto é, os estudantes de inglês, na verdade, devem tomar consciência da importância de aprenderem essa língua de grande poder para usá-la em seu favor, enxergando-se como usuários legítimos da língua e não apenas meros aprendizes, ou quando muito, falantes nativos fracassados. Para isso, é desejável que os docentes tenham, pelo menos, um olhar mais criterioso no tocante aos conteúdos que são abordados em sala de aula, no intuito de discutir de forma crítica discursos como os descritos abaixo: 
até mesmo no salário, que costuma ser maior do que o salário de quem não fala outro idioma.

[P2] A língua inglesa opera uma importância grandiosa no mundo atual [...] visto que, o mercado de trabalho é exigente e o inglês está entre essas exigências.

[P3] A cultura americana é muito rica.

[Aluno] Não sei nem português direito...

Segundo Graddol (2006, p. 71), "em um mundo globalizado e pós-moderno, um modelo de educação [linguística] particularmente diferente emergiu". Assim, as velhas práticas de ensino como, por exemplo, o estudo interminável de compêndios gramaticais que, por muito tempo foram adotadas nas nossas aulas de LE, não são mais compatíveis com esse cenário diversificado, tecnológico, ultraveloz, em que a língua em uso chega a qualquer um, em fração de segundos e de forma constante, para não dizer, avassaladora.

Frente a isso, ainda foi possível perceber no ambiente investigado que o mito do falante nativo como o modelo ideal ainda se encontra fortemente presente no imaginário de professores e alunos, como podemos observar na fala abaixo:

[P3] Faço, de ano em ano, em São Paulo, uma capacitação em inglês. São duas semanas. Todo ano eu faço essa capacitação de 15 dias, com professores nativos mesmo.

A partir dessa percepção, é provável que essa crença também permaneça neste e em tantos outros contextos de ensino de língua inglesa pelo mundo afora. O que se pode inferir, nesse pormenor, é que, no Brasil, a educação de LE ainda é conduzida tendo como base pedagogias universalizadas oriundas dos chamados países centrais, neste caso, EUA e Inglaterra. No entanto, como se sabe, os estudos voltados para o ILF já questionam tais premissas, deixando claro, entre outras coisas, que não é necessariamente a figura do nativo falante que irá propiciar o conhecimento mais eficaz de uma determinada língua, uma vez que, conforme Widdowson (1994), um indivíduo poderá se tornar competente numa nova língua no momento em que ele for capaz de apropriar-se, com autonomia, desse idioma e não subjugar-se às regras estabelecidas por outros. Em outras palavras, não são os falantes que são dominados pela língua, mas eles que a dominam.

A conscientização sobre a condição do inglês seria um passo extremamente importante para que professores e alunos, nos mais diversos contextos, compreendessem que o acesso a essa língua não significa se filiar a qualquer cultura ou tornar-se membro de uma determinada comunidade de língua inglesa. Ao contrário, o seu domínio por um maior número de pessoas, em especial aquelas que estão às margens, significaria a democratização de um dos bens culturais mais caros à globalização, levando, finalmente, essas populações excluídas a se sentirem protagonistas de um jogo global que, hoje, gostemos ou não, se joga em inglês. 
Dando seguimento à pesquisa, os dados confirmaram a suposição de que os professores colaboradores parecem crer que só existem, no máximo, dois padrões da língua inglesa, ou seja, o inglês americano e o inglês britânico, como podemos ver nas falas abaixo:

[P1] Eu costumo ensinar o inglês americano. Sempre tento comparar com o britânico.

[P2] Eu costumo ensinar o inglês britânico.

[P3] Eu costumo ensinar o inglês americano.

Tal conduta, na nossa visão, prima pela manutenção da ideia de que há realmente uma supremacia de um inglês tido como mais correto, mais bonito, hegemônico, fortalecendo a já histórica posição privilegiada desses dois países na nossa sociedade, e também expondo a relação de poder que, até então, eles exercem sobre nós:

\footnotetext{
Exceto de aula observada:

P3 explica que comparative of inferiority é marcado pela forma: less + adjective + than $\mathrm{E}$ exemplifica: Bruna is less pretty than Meg. Então, esclarece que a palavra pretty pode ser pronunciada da seguinte forma: /'prit.il em britânico ou então /'priț-/ em americano. Da mesma forma, quando se fala: See you later. Later no inglês britânico fala-se /'leı.tor/ e no inglês americano fala-se o /'ler.tə\%.
}

Como é de se imaginar, nenhuma língua passa incólume à ação de seus novos usuários. Com o inglês não seria diferente. Portanto, não faz sentido algum perpetuarmos a prática subalterna e ultrapassada de se formar nas nossas salas de língua inglesa 'papagaios' imitadores de vozes de falantes nativos. Como já salientado, trata-se de uma quimera que, no nosso ponto de vista, deve ser desconstruída desde o primeiro dia de aula. O inglês que viaja pelo mundo está sentindo muito bem os efeitos de se tornar a segunda, terceira, quarta língua de um grande número de falantes. E como ressalta Nault (2006, p. 316),

Os falantes globais de língua inglesa não estão simplesmente absorvendo conhecimento passivo ou, como papagaios amestrados, reproduzindo o inglês falado nos tradicionais centros de influência. Na verdade, eles estão, de maneira ativa, reinterpretando, reformulando e redefinindo o inglês, tanto oralmente quanto por escrito.

Embora, por força da tradição, muitos professores tenham predileção pelo inglês norte-americano e/ou britânico e acreditem que utilizam essas variedades em suas aulas, no nosso ponto de vista, considerando a condição do inglês como língua franca, é de suma importância que outros ingleses, tais como aqueles falados em países como África do Sul, Índia, Nigéria, Jamaica, entre outros, sejam ao menos informadas aos alunos. Dessa forma, uma maior compreensão da multiplicidade dos aspectos linguísticos e culturais que a língua inglesa proporciona seria coerentemente possibilitada aos estudantes. No entanto, a partir de 
algumas respostas de nossos participantes, tal questão ainda não parece algo plenamente resolvido:

[P1] O [inglês] britânico é muito correto e o americano já tem aquelas diferenças, já tem gírias e é isso que eles gostam, de falar naturalmente [...] o inglês americano é mais usado por conta do material que a gente recebe.

[P2] Eles vão conhecer as duas [pronúncias]; o professor em sala de aula, ele é quem vai ensinar, então ele tem que aprender um e outro pra ser mais claro pra explicar.

[P3] Eu levo as minhas aulas com o americano, pois foi o que eu aprendi, mas não descarto o britânico.

Apesar de a língua inglesa, no atual momento, deter uma posição privilegiada, nenhuma língua pode ser vista como superior. Logo, é válido avaliar que o inglês que está aí no dia a dia, que se fala com o mundo todo, não é somente a língua tida como aquela emanada dos chamados centros de sua custódia, mas o idioma falado por diferentes povos de diferentes nações, nos mais diversos usos e propósitos. Por isso, na perspectiva que defendemos, emerge a necessidade de que haja uma ampla divulgação do status dessa língua e as suas implicações, sob pena de muitos professores continuarem a ocupar a posição incômoda de supostos agentes manipuladores de uma língua que representa um determinado país e uma cultura estereotipada que subalterniza as outras a seu redor. Algo muito longe, portanto, de oferecer o acesso a um idioma que possa proporcionar o contato, a comunicação, a união, o diálogo entre os povos. Neste aspecto em particular, parece que um dos nossos participantes tem algo bastante positivo a nos dizer:

[P2] Eu deixo claro o quanto é importante estudar e aprender esse idioma que é falado em diversos países e que a todo dia o vivenciamos nas lojas, lanchonetes, enfim, procuro ser persuasiva e acredito, mediante perguntas que faço na sala de aula, que eles percebem que é importante e muito significativo aprender uma língua inglesa.

Por outro lado, cumpre reforçar que, independentemente de se reconhecer a importância do inglês, não se pode ter uma atitude de endeusamento dessa língua ou uma postura ingênua em relação às consequências de seu avanço pelo mundo, mas estar consciente e seguro o bastante para se distinguir entre a língua que se fala em determinados países anglófonos da língua que se fala mundialmente. Ou melhor, torna-se imprescindível perceber que esse idioma assume cada vez mais sua condição ampla e comum de língua franca mundial. E isso tem repercussões importantes. É um fenômeno que precisa ser tratado de forma política, já que, como se sabe, é a língua que nos une apesar de todas as nossas diferenças. Da mesma forma, deve-se concebê-la como uma língua de comunicação entre diferentes povos, de acesso, de alteridade, garantindo, seguramente, aos seus falantes a 
capacidade de desenvolver os sentidos de cidadania, responsabilidade e aceitação do diferente.

A reboque de tal reflexão, vale salientar que é importante que seja fomentada constantemente a valorização da língua e cultura(s) maternas e de outras culturas que não sejam as tradicionais, dado que tais posturas são primordiais para a formação de usuários questionadores e integrados à sociedade contemporânea. Os nossos informantes, de certa forma, já trazem um pouco desse sentimento, como se pode ver por algumas de suas afirmações:

[P1] Eu costumo mostrar a cultura dos principais países que falam a língua inglesa, gosto de fazer comparações com o nosso país sobre a política, renda, curiosidades.

[P2] Acho sim importante eles aprenderem a cultura dos países que falam a língua inglesa, pois permite que eles ampliem o seu conhecimento e dessa forma promove momentos de interação e reflexão no ambiente escolar.

[P3] Acho importante comparar culturas, formas distintas de vivenciar e comemorar datas e celebrações.

\section{Considerações finais}

Este breve texto, como mencionado, teve como objetivo trazer algumas discussões oriundas de um estudo acadêmico cujo propósito foi acompanhar três professores de inglês da educação básica em suas jornadas de trabalho na cidade de Caetité/Bahia. Na nossa busca em averiguar como está sendo conduzido o ensino de inglês naquela localidade, em um cenário de globalização, notamos que os educadores, apesar de empreenderem significativos esforços para proporcionar aos seus estudantes um ensino de qualidade, ainda se veem diante de muitas adversidades, tais como, superlotação de aulas, carga horária esquálida, uma aparente falta de motivação dos alunos em aprender uma nova língua, poucos recursos tecnológicos, entre outros, para obter um bom resultado nessa difícil e complexa empreitada.

Em face de nossa investigação, embora apresentada aqui de forma bastante sucinta, percebemos também que os educadores ainda reproduzem práticas tidas como tradicionais na orientação de suas atividades como, por exemplo, a escolha maciça de materiais e sistemas de avaliação importados de países anglófonos, além do engajamento em programas de treinamento docente pouco apropriados para um processo de ensino e aprendizagem da língua inglesa que se imagine interculturalmente sensível. Além disso, nossos participantes, infelizmente, parecem ainda estar muito focados na aquisição de recursos estritamente linguísticos, deixando, entre outros aspectos, de considerar qualquer associação de sua prática 
profissional com questões sociais, políticas ou mesmo culturais, inter-relacionadas com sua realidade e a de seus educandos.

Nessa direção, Cox e Assis Peterson (1999) enfatizam que os professores de inglês deveriam ter consciência da dimensão política do ensino desta língua, ao mesmo tempo em que deveriam questionar e confrontar as ideologias subjacentes à natureza de qualquer língua. Como aponta Bourdieu (1983, p. 160-161), “a língua não é somente um instrumento de comunicação ou mesmo de conhecimento, mas um instrumento de poder". Daí ser absolutamente legítimo afirmar que a língua inglesa, nos tempos de hoje, representa um dos mais importantes e valiosos 'capitais culturais' que uma pessoa pode vir a possuir. E que precisa ser democratizada.

Como nenhuma língua é uma entidade estática, pura, neutra, é preciso adotarmos uma definição crítica do que, de fato, representa a língua inglesa neste contexto globalizado, dado que esse idioma, por ser dotado de uma alta carga política e ideológica, afeta, por consequência, o mundo contemporâneo nos mais diversos níveis. E por afetar a vida real, tais desdobramentos não podem ser ignorados pela pedagogia de LE, em especial no ambiente da escola pública onde a disciplina, historicamente, ocupa uma posição tida como menor.

Por conta disso, e dos entraves estruturais aqui já citados, é possível observar que os alunos, com muita frequência, se mostram desmotivados, desestimulados para o aprendizado do inglês, pois as aulas ainda carecem de iniciativas mais contundentes de interação, significação e encantamento com a possibilidade de, nesses espaços escolares, juntarem-se de forma produtiva e salutar línguas e culturas (maternas e estrangeiras), visando a um ganho bem maior, que é exatamente a implosão do mito de que não se aprende inglês na escola regular.

A fim de evitar, ou pelo menos, minimizar, tais práticas e comportamentos, é oportuno registrar um posicionamento de Mendes (2007), que sugere como alternativa para um ensino de línguas mais contextualizado e significativo, uma abordagem que possa, efetivamente, promover o diálogo entre as mais diversas culturas. Para esta autora, vale lembrar que o sentido que se deve buscar nas nossas aulas é o de língua que, gradualmente, se 'desestrangeiriza' (cf. ALMEIDA FILHO, 2002), permitindo ao aprendiz "experimentar situações de comunicação com a língua alvo que vão além do simples contato com esquemas disponíveis no sistema linguístico" (MENDES, 2007, p. 130).

Portanto, para arrematar as breves discussões empreendidas ao longo do texto, vale citar Freire (2013), quando ele afirma que "a prática pedagógica é um ato político por excelência”. Mediante essa premissa, com muita esperança e otimismo, acreditamos que 
poderemos alcançar aquele estágio em que os professores de língua inglesa se reconheçam conscientes e comprometidos com esse tipo de conduta na sala de aula, visto que se trata de um dos caminhos que possibilitaria a construção de uma pedagogia de língua inglesa (e de línguas em geral) baseada na aprendizagem de uma língua real e não idealizada.

Por fim, acreditamos que o ensino de inglês deve propiciar aos seus aprendizes a utilização dessa língua como um meio de comunicação entre os diferentes grupos sociais. De tal sorte, deve ser um ensino essencialmente pautado numa pedagogia mais crítica, reflexiva, dialógica, no intuito de viabilizar uma sociedade mais justa, em que haja, entre tantas outras coisas benéficas, o reconhecimento do outro e o respeito aos princípios da igualdade e da diferença. Em outras palavras, quando se imaginar que a aquisição de uma língua poderosa como o inglês pode trazer todos esses ganhos para os nossos alunos e futuros falantes, temos certeza que a educação linguística como um todo, do trabalho do formador à prática docente, avançará nos seus princípios teóricos e na sua prática em outras bases.

Se encararmos, genuinamente, a pedagogia de língua inglesa sob a perspectiva de uma língua franca global, suas implicações e suas consequências, os resultados que daí poderão advir serão extremamente benéficos para todos, sem exceções e privilégios. Este é um caminho complexo e desafiador que teremos que trilhar. A realidade mundial contemporânea nos impõe tal tarefa. Apesar de tantas dificuldades, haverá sempre tempo para desconstruir e reconstruir nossas certezas. Basta coragem para pensarmos diferente e nos unirmos àqueles que, com vontade e determinação, estão sempre dispostos a se lançar ao novo, rompendo barreiras e desobedecendo limites. Não é mesmo este o papel do verdadeiro educador?

\section{REFERÊNCIAS}

AGAR, M. Language shock: Understanding the culture of conversation. New York: William Morrow, 1994.

ALMEIDA FILHO, J. C. P. de. Língua além de cultura ou além de cultura, língua? Aspectos do ensino da interculturalidade. In: CUNHA, M. J.; SANTOS, P. (Org.). Tópicos em português língua estrangeira. Brasília: EDUNB, 2002, p. 210-215.

ANDRÉ, M. E. D. A. de. Etnografia da Prática Escolar. 11a. ed. São Paulo: Papirus, 1995.

BHABHA, H. K. O local da cultura. Trad. de Myriam Ávila et al. Belo Horizonte: Editora UFMG, 1998.

BLOMMAERT, J. The sociolinguistics of globalization. New York, USA: Cambridge University Press, 2010.

BOURDIEU, P. A economia das trocas linguísticas. In: ORTIZ, R. (Org.). Bourdieu. São Paulo: Ática. Coleção Grandes Cientistas Sociais, Vol. 39, 1983, p. 156-183. 
COGO, A. Strategic use and perceptions of English as a lingua franca. Poznan Studies in Contemporary Linguistics, Vol. 46, No. 3, p. 295-312, 2010.

COGO, A. English as a lingua franca: Descriptions, domains and applications. In: BOWLES, H.; COGO, A. (Ed.). International perspectives on English as a lingua franca: pedagogical insights. New York: Palgrave/Macmillan, 2015, p. 1-12.

COGO A.; DEWEY, M. Analysing English as a lingua franca: a corpus-driven investigation. New York: Continuum, 2012.

COX, M. I. P.; ASSIS-PETERSON, A. A. de. Critical Pedagogy in ELT: images of Brazilian teachers of English. Tesol Quarterly, Vol. 33, No. 3, p. 433-452, 1999.

CRYSTAL, D. English as a Global Language. 2. ed. Cambridge: Cambridge University Press, 2003.

FREIRE, P. Pedagogia da autonomia: saberes necessários à prática educativa. 47. ed. Rio de Janeiro: Paz e Terra, 2013.

GIL, A. C. Como elaborar projetos de pesquisa. 3. ed. São Paulo: Editora Atlas, 2002.

GIROUX, H. A. Um livro para os que cruzam fronteiras. In: GADOTTI, M. (Org.). Paulo Freire: uma bibliografia. São Paulo: Cortez Editora, 1996, p. 569-570

GRADDOL, D. English Next: why global English may mean the end of English as a foreign language. The British Council. London: The English Company, 2006.

JENKINS, J. Current perspectives on Teaching World Englishes and English as a Lingua Franca. Tesol Quarterly, Vol. 40, No. 1, p. 157-181, 2006.

MENDES, E. A perspectiva intercultural no ensino de línguas: uma relação "entre-culturas". In: ALVAREZ, M. L. O.; SILVA, K. A. da. (Org.). Linguística aplicada: múltiplos olhares. Campinas, SP: Pontes, 2007, p. 119-139.

MENDES, E. Aprender a ser e a viver com o outro: materiais didáticos interculturais para o ensino de português LE/L2. IN: SCHEYERL, D.; SIQUEIRA, D. S. P. (Org.). Materiais didáticos para o ensino de línguas na contemporaneidade: contestações e proposições. Salvador: EDUFBA, 2012, p. 355-377.

MOITA LOPES, L. P. da. Oficina de Linguística Aplicada: a natureza social e educacional dos processos de aprendizagem de ensino/aprendizagem de línguas. Campinas, SP: Mercado de Letras, 1996.

MOITA LOPES, L. P. da. Inglês e globalização em uma epistemologia de fronteiras: ideologia linguística para tempos híbridos. D.E.L.T.A, Vol. 24, No. 2, 2008, p. 309-340.

NAULT, D. Going global: Rethinking culture teaching in ELT contexts. Language, Culture and Curriculum, Vol. 19, No. 3, p. 314-328, 2006.

ORTIZ, R. Mundialização: saberes e crenças. São Paulo: Brasiliense, 2006.

PENNYCOOK, A. English in the World/The World in English. In: TOLLEFSON, J. W. (Ed.). Power and Inequality in Language Education. Cambridge: Cambridge University Press, 1995, p. 34-58.

PENNYCOOK, A. English in the World/The World in English. In BURNS, A.; COFFIN, C.. (Ed.). Analysing English in a global context: a reader. London/New York: Routledge, 2001, p. 78-89.

PENNYCOOK, A. A Linguística Aplicada nos anos 90: em defesa de uma abordagem crítica. In: SIGNORINI, I.; CAVALCANTI, M. C. (Org.). Linguística Aplicada $e$ Transdisciplinaridade: questões e perspectivas. São Paulo: Mercado de Letras, 2007, p. 2146.

RAJAGOPALAN, K. A geopolítica da língua inglesa e seus reflexos no Brasil. RAJAGOPALAN, K; LACOSTE, Y. (Org.). A geopolítica do inglês. São Paulo: Parábola Editorial, 2005, p. 135-159.

SEIDLHOFER, B. Closing a conceptual gap: the case for a description of English as a Lingua Franca. International Journal of Applied Linguistics, Vol. 11, No. 2, p. 133-158, 2001. 
SEIDLHOFER, B. Understanding English as a lingua franca. Oxford: Oxford University Press, 2011.

SIFAKIS, N. ELF awareness as an opportunity for change: a transformative perspective for ESOL teacher education. Journal of English as a Lingua Franca. Vol. 3, p. 317-335, 2014.

SIQUEIRA, D. S. P.; BARROS, K. S. Por um ensino intercultural de inglês como língua franca. Estudos Linguísticos e Literários, Vol. 48, p. 5-39, 2013.

WIDDOWSON, H. G. The ownership of English. Tesol Quarterty, Vol. 28, No. 2, p. $377-$ 389, 1994. 